\title{
Monitoring the Degradation of 4-Sulfonyldipenyl-Pyromellitic Dianhy- dride-Based Polyamic Acid by Trametes Versicolor
}

\author{
İdris Yazgan* \\ Department of Biology, Center for Biosensors and Material Science, Faculty of Science and Art, Kastamonu University- \\ Kastamonu, Turkey \\ *iyazgan@kastamonu.edu.tr
}

Received: 12 September 2018

Accepted: 08 February 2019

DOI: $10.18466 /$ cbayarfbe. 459381

\begin{abstract}
Polyamic acid (PAA) polymers have been utilized over 60 years in industry as precursors of polyimide, and currently direct utilization of PAA polymers have got great attention for material science applications. Mass utilization of synthetic polymers pose threat to living organisms and nature, so their effective degradation is important. In this study, for the first time, degradation of 4-sulfonyldipenyl-pyromellitic dianhydride based PAA (DSPAA) polymers were performed in batch bioreactor system. ${ }^{1} \mathrm{H}$ COSY NMR was utilized to enlight the possible mechanism behind Tramates versicolor mediated degradation of DSPAA polymer. Elimination of aromatic peaks belong to DSPAA polymer and its amine monomer were monitored to evaluate the degradation while formation of new peaks was taken into account to propose possible degradation pathway. NMR studies revealed that 20-day incubation in the designed media is enough to totally eliminate $1 \mathrm{mg} / \mathrm{mL}$ DSPAA. The findings can contribute to the knowledge of fungi mediated aromatic polymer degradation, which is accepted a promising way to eliminate polymer pollution.
\end{abstract}

Keywords: Bioreactor, Biodegradation, NMR, Polyamic acid, Trametes versicolor.

\section{Introduction}

Polymers are indispensable part of daily lives. Dramatic increase in their production and consumption, reached over 300 million tons in 2015 [1], has lead accumulation of persistent waste in nature that causes threat to living organisms and environment [2]. This problem is not limited to the bulk plastic discarded into environment, but also microplastics are accumulating in costs and sea which also posing dramatic threat to the living organisms [3]. Therefore, their controlled degradation before they reach into the environment is an emerging need.

Chemical, physical and biological approaches have been developed over the years to cope with this problem. Among these methods, biological approaches (biodegradation) are superior to the chemical degradation approaches with their capabilities to break the polymer into water and carbon-dioxide.

Biodegradation of the polymers is a multidimensional phenomenon [4] involves microorganisms and/or enzymes including bacteria and fungi that are capable of metabolizing plastics into water and carbon-dioxide owing to their diverse extracellular oxido-reductases [2, 5]. Chemical [6] and physical properties of the polymers determine their fate in biodegradation [7]. For instance, increase in molecular weight of the polymer results in decreased biodegradability [7]. A variety of microorganisms including bacteria (e.g. Pseudomonas and Pastalotiopsis) and fungi (e.g. Aspergillus and Trametes) have been reported with their performances in degradation of different type of plastics $[2,8]$. The microorganisms can use same or distinctly different extracellular enzyme-sets during degradation of same polymer $[2,9]$. In addition to the microorganism's performance itself, environmental factors including light, heat and mechanical and chemical exposures pose effect on polymeric materials' resistance to biodegradation [4].

Basidiomycetes are known with their high performance in degradation of natural lignin and cellulose in environment to sustain decomposition of death plants owing to the extracellular enzymes including lignin peroxidase, laccase, Mn-peroxidase and such other peroxidases as multifunctional peroxidase [8]. In addition to these, Basidiomycetes can catalyze breakdown of xenobiotics and lignin via nonenzymatic pathway where they produce highly reactive species and release them into the media to oxidase the target molecules [8]. All these make them capable of degrading the man-made polycyclic aromatic hydrocarbons, dyes, 
inorganic ions, azo-compounds, pesticides and xenobiotics and so on [8]. Among the species in Basidiomycetes, Trametes versicolor is known with its aggressive nature in degradation of phenolic compounds including chlorinated polyphenols [10], natural lignocellulosic polymers [11, 12], poly(lactic)acid [1], phenanthrene [9] and petroleum-based Nylon [13].

It is critical to annotate the degradation mechanism of the polymers in order to develop effective approaches to solve plastic related environmental issues [2]. Polyamic acid has been used as the precursor of polyimide synthesis [14], which is one of the most widely used polymers in electronics to material science [15], so their degradations are critical. In this study, for the first time, Trametes versicolor was used as the model organism to breakdown 4-sulfonyldipenyl-pyromellitic dianhydride poly(amic)acid (DSPAA) under controlled experimental conditions, whose degradation was monitored with by ${ }^{1} \mathrm{H}$ COSY NMR. The findings revealed that Trametes versicolor could breakdown DSPAA within 20-days under controlled, which can call further research to model elimination of polyamic acidbased polymers including polyimide before they are discarded into the environment that can help to reduce plastic related environmental problems.

\section{Material and Methods}

\subsection{Materials}

Pyromellitic dianhydride (PMDA) and 4-sulfonyldianiline (DSA) were purchased from Sigma-Aldrich [MO, the USA]. N,N'-dimethylacetamide, Potato-dextrose agar (PDA), YPD Broth, glucose, were purchased from Merck [Ankara, Turkey]

\subsection{Synthesis of Polyamic acid Membranes}

Synthesis of DSPAA polymers are reported elsewhere [11]. Briefly, a $0.20 \mathrm{M}$ viscous solution of DSPAA was prepared by dissolving 4-sulfonyldianiline in anhydrous $\mathrm{N}, \mathrm{N}$ '-dimethylacetamide (DMAC) followed by the addition of pyromellitic dianhydride, and then it was left for $18 \mathrm{~h}$ incubation to obtain mature DSPAA. The DSPAA solution, was then casted on a clean glass surface for $12 \mathrm{~h}$ incubation under hood to fully plasticized DSPAA polymeric films.

\subsection{Solutions and Media}

\subsubsection{Trace-metal Solution}

We used a modified trace metals solution described elsewhere [11] containing $20 \mathrm{mM} \mathrm{FeSO}{ }_{4} .7 \mathrm{H}_{2} 0,2 \mathrm{mM}$ $\mathrm{CuSO}_{4} .5 \mathrm{H}_{2} \mathrm{O}, 5 \mathrm{mM} \mathrm{ZnCl} 2,30 \mathrm{mM} \mathrm{MnSO}_{4} \cdot \mathrm{H}_{2} 0,6 \mu \mathrm{M}$ $\mathrm{CoCl}_{2} \cdot 6 \mathrm{H}_{2} 0,1 \mathrm{mM} \mathrm{NiCl}_{2} \cdot 6 \mathrm{H}_{2} 0$, and $1 \mathrm{mM} \mathrm{MoCl}$. Particularly, higher manganese $(\mathrm{Mn})$ concentration was targeted since white-rot fungi use Mn to break-down polycyclic aromatic polymers [16].

\subsubsection{Degradation Medium}

A bioreactor (125 mL Pyrex ${ }^{\mathrm{TM}}$ narrow-necked Erlenmeyer) was employed for the degradation process. T.versicolor $\left(\mathrm{ATCC}^{\circledR} 42530^{\mathrm{TM}}\right.$ ) was first grown on PDA containing 10 $\mu \mathrm{g} / \mathrm{g}$ DSPAA, followed by spores were collected from the medium. This contained $10 \mathrm{mg} / \mathrm{mL}$ YPD medium, 0.2 $\mathrm{mg} / \mathrm{mL}$ D-glucose, $1 \%$ L-glutamine, $25 \mu \mathrm{L} / \mathrm{mL}$ trace-metal solution and $10 \mathrm{mg} / \mathrm{mL}$ Peptone. The $\mathrm{pH}$ of the medium was adjusted to 5.5 using $10 \mathrm{mM}$ hydrochloric acid before autoclaving. The batch-bioreactor volume was $100 \mathrm{~mL}$ containing $10^{3}$ spores $/ \mathrm{mL}$ of T.versicolor, and the membrane was at $100 \mathrm{mg}$ weight. All the experimentations were done at room temperature. Continuous stirring was performed at $200 \mathrm{rpm}$.

\subsection{Monitoring Degradation}

For each NMR run, $1 \mathrm{~mL}$ of solution from the degradation medium was placed into a $1.5 \mathrm{~mL}$ polyproline micro-centrifuge tube. The sample was frozen in $-20^{\circ} \mathrm{C}$ overnight, and then lyophilized for $24 \mathrm{~h}$. The resulting solid sample was dissolved in $1 \mathrm{~mL}$ of $\mathrm{D}_{2} \mathrm{O}$. Degradation of the polymers was monitored via ${ }^{1} \mathrm{H}$ COSY techniques. All NMR experimentations were performed at Bruker Avance III 400 run by TopSpin $3.5 \mathrm{pl}$.

\section{Results and Discussion}

Degradation of DSPAA by T.versicolor was monitored by analyzing the aromatic groups of DSPAA polymer and DSA monomer. Due to the fact that samples from degradation medium were run in $\mathrm{D}_{2} \mathrm{O}$, amino groups of DSPAA were not visible in ${ }^{1} \mathrm{H}$ COSY NMR spectra. Previous studies revealed that monitoring the aromatic groups provide valuable information on degradation mechanism [11].

DSPAA polymer was dissolved in DMSO- $\mathrm{d}_{6}$ while degradation samples were dissolved in $\mathrm{D}_{2} \mathrm{O}$. Therefore, ${ }^{1} \mathrm{H}$ shifts were not expected to overlap despite of the fact that ${ }^{1} \mathrm{H}$ COSY spectra of DSPAA and DSA were obtained same in both cases.

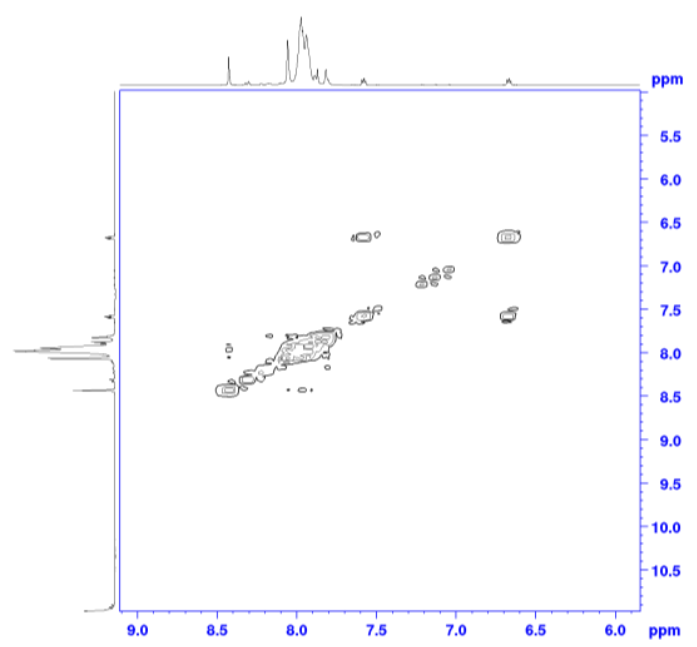

Figure 1. ${ }^{1} \mathrm{H}$ COSY of DSPAA. Experimentation was done. 
in $\mathrm{D}_{2} \mathrm{O}$ solvent.

As seen from Figure 1, aromatic protons on DSA monomer gave coupling at 6.67-7.57 ppm as shown in literature [11]. Long range coupling on DSA monomer from degradation mixture in $\mathrm{D}_{2} \mathrm{O}$ was obtained at $6.92-7.75 \mathrm{ppm}$, which was observed for day 1 (Figure 2) and day 5 (Figure 3) while the coupling was not observed for $20^{\text {th }}$ day sampling (Figure 4$)$. The coupling was also observed for $10^{\text {th }}$ and $16^{\text {th }}$ days of sampling (data not shown).

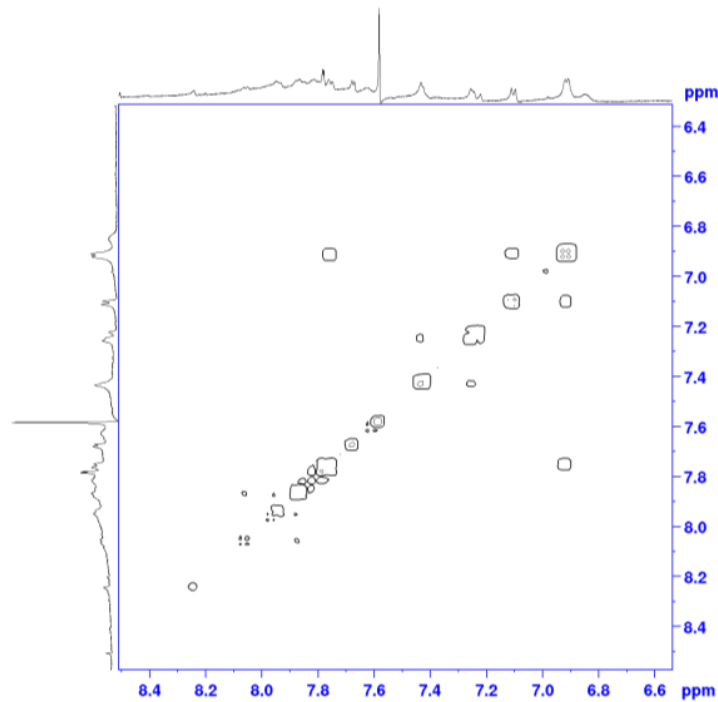

Figure 2. $1^{\text {st }}$ day ${ }^{1} \mathrm{H}$ COSY of DSPAA from degradation medium. Experimentation was done in $\mathrm{D}_{2} \mathrm{O}$ solvent.

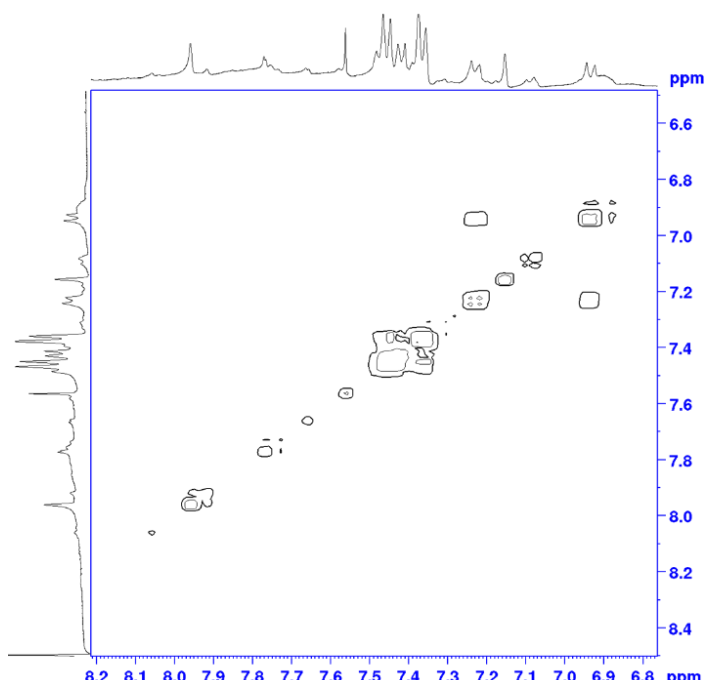

Figure 4. $20^{\text {th }}$ day ${ }^{1} \mathrm{H}$ COSY of DSPAA from degradation medium. Experimentation was done in $\mathrm{D}_{2} \mathrm{O}$ solvent.

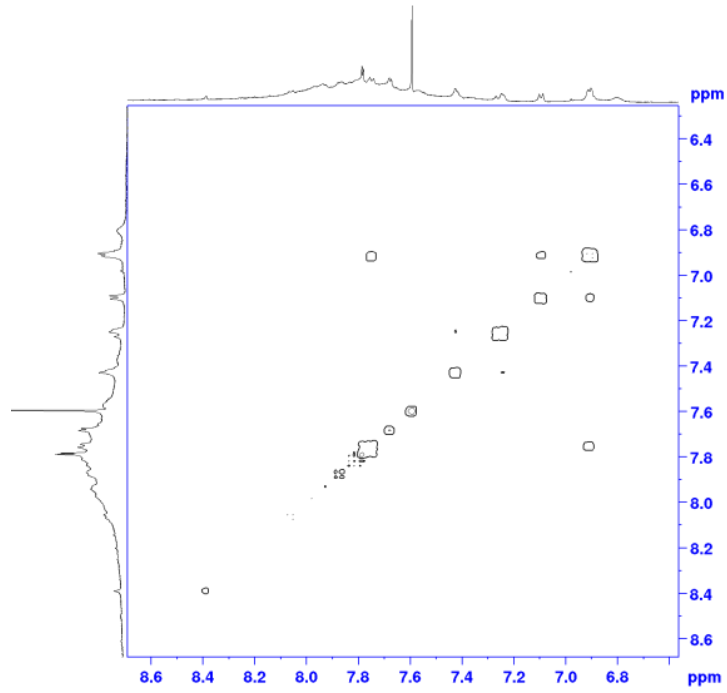

Figure 3. $5^{\text {th }}$ day ${ }^{1} \mathrm{H}$ COSY of DSPAA from degradation medium. Experimentation was done in $\mathrm{D}_{2} \mathrm{O}$ solvent.

As shown in Figure 1, DSPAA polymer gave 5 aromatic peaks between 7.81-8.42 ppm range which were observed for DSPAA polymer in degradation media (Figure 2 and Figure 3). As seen in Figure 4, new long-range coupling at 6.94-7.22 ppm was observed, which was also present for $1^{\text {st }}$ ( $24 \mathrm{~h}$ incubation) and $5^{\text {th }}$ days of sampling. However, the coupling was not present for DSPAA polymer. This might refer to that T.versicolor was breaking down DSA monomer along with DSPAA degradation.

As seen from Figure 4, aromatic peak profile of $20^{\text {th }}$ day dramatically changed in comparison to $1^{\text {st }}$ and $5^{\text {th }}$ day samples spectra. Formation of new doublets and singlets at aromatic range in $20^{\text {th }}$ day spectra can also refer to that new molecules are forming by fungal metabolism along with oxidation of DSPAA polymer and DSA monomer. Therefore, the degradation possibly followed the mechanism shown in Figure 5. 


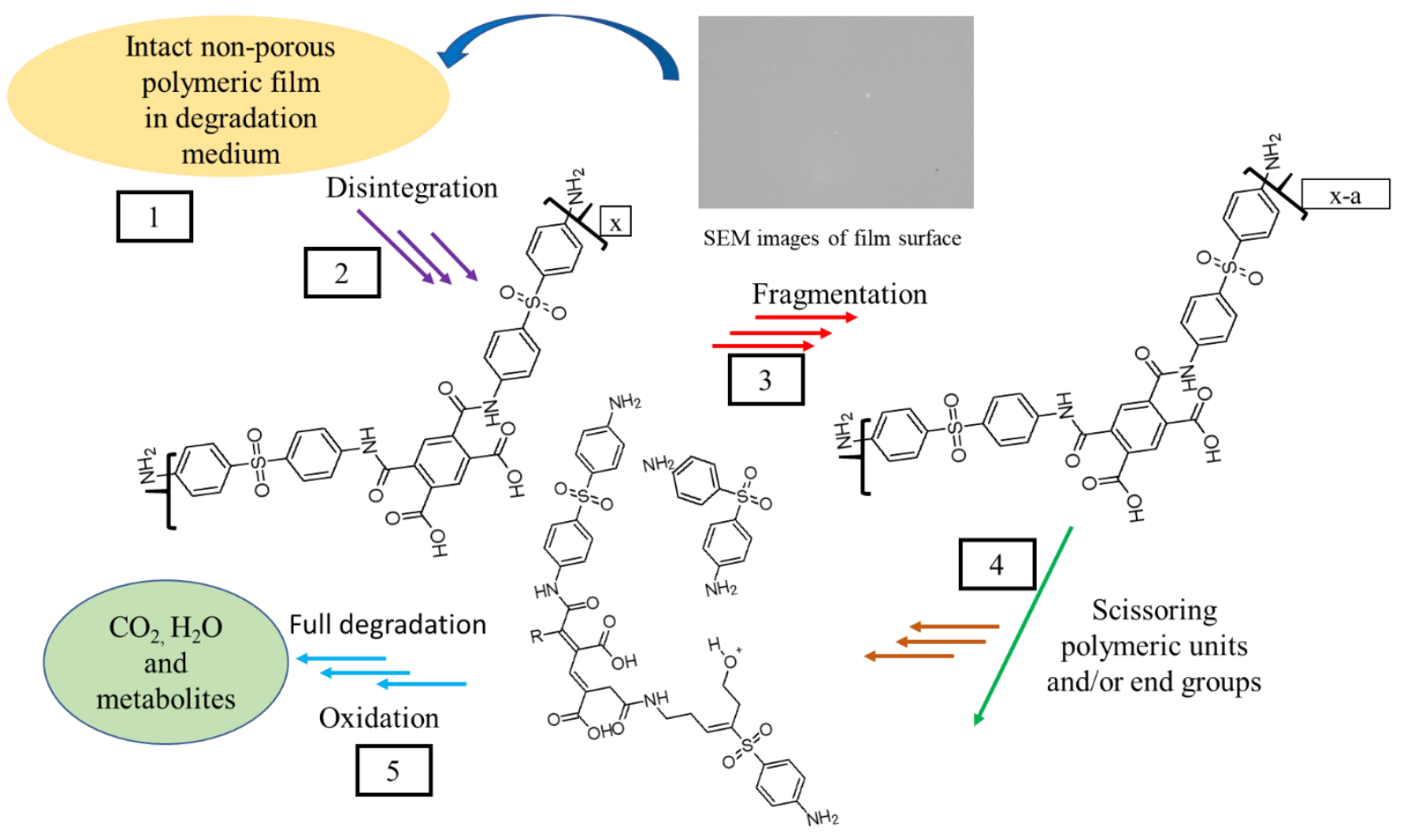

Figure 5. Proposed degradation of DSPAA polymer by T. versicolor. (1) DSPAA polymer, (2) fungal activity and mediummediated disintegration of DSPAA polymer, (3) fragmentation of DSPAA by fungal activity, (4) disintegration of individual polymers, and (5) further elimination of broken down DSPAA polymers.

As seen in Figure 4, new peaks at 7.56 ppm arose upon degradation of DSPAA, which could refer to presence of aliphatic amide group [17] as illustrated in Figure 5. The observation is also supported with the new long-range coupling at 7.21-6.92 ppm. Similar shifts can be seen for indolamines as well [17], which is possible due to the fact that certain metabolites can be released into the media by T.versicolor [18]. The degradation of DSPAA polymer, particularly diahydride source, can follow formation of carboxyl groups as shown for organic textile dyes [19].

Degradation of 4,4-oxydianiline/pyromellitic dianhydride based polyamic acid by Trichaptum biforme and Fusarium oxysporum was shown previously shown [11], where monomer formation was not observed. This could be related to either fungi-specific reasons or the monomer composition. However, in all cases, degradation of polyamic acid polymers by fungi took shorter than expected times. This could be related to that PAA can chelate a variety of metals [11] from the degradation media. In the presence of chelating agent, manganese-peroxidase (which is released into the media by T.versicolor) triggers formation of $\mathrm{Mn}^{3+}$ chelator complex which is a highly aggressive oxidizer for phenolic compounds [8], what possibly helped T.versicolor to break DSPAA less than 3-week period.

\section{Conclusion}

In this study, biodegradation of sulfone group containing polyamic acid polymers (DSPAA) were successfully degraded using batch culture of T. versicolor. Monitoring the fungal degradation using ${ }^{1} \mathrm{H}$ COSY NMR under experimentally controlled conditions will contribute the understanding of the biodegradation of aromatic polymers.

\section{Acknowledgement}

We acknowledge internal funds of Kastamonu University, the fund number is KÜ-BAP01/2018-33. Thanks to Dr. Abdurrahman Gümüş (İzmir Institute of Technology) for his help to perform NMR studies.

\section{Author's Contributions}

İdris Yazgan: Drafted and wrote the manuscript, performed the experiment and result analysis.

\section{Ethics}

There are no ethical issues after the publication of this manuscript.

\section{References}

1. Emadian, SM, Onay, TT, Demirel, B. 2017. Biodegradation of bioplastics in natural environments. Waste Management; 59: 526-536.

2. Russell, JR, Huang, J, Anand, P, Kucera, K, Sandoval, AM, Dantzler, 
KW, Hickman, D, Jee, J, Kimovec, FM, Koppstein, D, Marks, DH, Mittermiller, PA, Núńez, SJ, Santiago, M, Townes, MA, Vishnevetsky, M, Williams, NE, Núńez-Vargas, MP, Boulanger, LA, Bascom-Slack, C, Strobel, SA. 2011. Biodegradation of polyester polyurethane by endophytic fungi. Applied Environmental Microbiology; 77: 6076-6084.

3. Dekiff, JH, Remy, D, Klasmeier, J, Fries, E. 2014. Occurrence and spatial distribution of microplastics in sediments from Norderney. Environmental Pollution; 186: 248-256.

4. Lucas, N, Bienaime, C, Belloy, C, Queneudec, M, Sivestre, F, NavaSaucedo, JE. 2008. Polymer biodegradation: Mechanisms and estimation techniques - A review. Chemosphere; 73: 429-442.

5. Ahmed, T, Shahid, M, Azeem, F, Rasul, I, Noman, M, Hameed, A, Manzoor, N, Manzoor, I, Muhammed, S. 2018. Biodegradation of plastics: current scenario and future prospects for environmental safety. Environmental Science and Pollution; 25(8): 7287-7298.

6. Witt, U, Yamamoto, M, Seeliger, U, Müller, RJ, Warzelhan, V. 1999. Biodegradable Polymeric Materials-Not the Origin but the Chemical Structure Determines Biodegradability. Angewandte Chemie International Edition; 30: 1438-1442.

7. Tokiwa, Y, Calabia, BP, Ugwu, CU, Aiba S. 2009. Biodegradability of plastics. International Journal of Molecular Sciences; 10: 37223742 .

8. Kulikova, NA, Klein, OA, Stepanova, EV, Koroleva, OV. 2011. Use of Basidiomycetes in Industrial Waste Processing and Utilization Technologies: Fundamental and Applied Aspects (Review). Applied Biochem Microbiology; 47: 565-579.

9. Young, D, Rice, J, Martin, R, Lindquist, E, Lipzen, A, Grigoriev, I, Hibbett, D. 2015. Degradation of bunker C fuel oil by white-rot fungi in sawdust cultures suggests potential applications in bioremediation. PLoS One; 10(6): e0130381.

10. Marco-Urrea, E, Pérez-Trujillo, M, Cruz-Morató, C, Caminal, G, Vicent, T. 2010. Degradation of the drug sodium diclofenac by Trametes versicolor pellets and identification of some intermediates by NMR. Journal of Hazardous Materials; 176: 836-842.
11. Yazgan, I. 2016. Novel Poly (amic) Acid Membrane Chemistries with Experimentally-controlled Pore size, Transport, and Disinfection Properties. Dissertation. State University of New York at Binghamton.

12. Erdem, E, Ucar, MC, Kaymaz, Y, Pazarlioglu, NK. 2009. New and different lignocellulosic materials from Turkey for laccase and manganese peroxidase production by Trametes versicolor. Engineering in Life Sciences; 9: 60-65.

13. Chonde-Sonal, G, Chonde-Sachin, G, Bhosale, PR, Nakade, DB, Raut, PD. 2012. Studies on degradation of synthetic polymer Nylon 6 by fungus Trametes versicolor NCIM 1086. International Journal of Environmental Science and Technology; 2: 2435-2442.

14. Scholes, CA, Ghosh, U. 2016. Helium separation through polymeric membranes: selectivity targets. Journal of Membrane Science; 520: 221-230.

15. Chen, JC, Wu, JA, Lee, CY, Tsai, MC, Chen, KH. 2015. Novel polyimides containing benzimidazole for temperature proton exchange membrane fuel. Journal of Membrane Science; 483: 144-154.

16. Hofrichter, M. 2002. Review: lignin conversion by manganese peroxidase (MnP). Enzyme and Microbial Technolgy; 30: 454-466.

17. Abraham, RJ, Griffiths, L, Perez M. 2013. 1H NMR spectra. Part 30: $1 \mathrm{H}$ chemical shifts in amides and the magnetic anisotropy, electric field and steric effects of the amide group. Magnetic Resonance in Chemistry; 51: 143-155.

18. Bose, A, Shah, D, Keharia, H. 2013. Production of indole-3-aceticacid (IAA) by the white rot fungus Pleurotus ostreatus under submerged condition of Jatropha seedcake. Mycology; 4: 103-111.

19. Campos, R, Kandelbauer, A, Robra, KH, Cavaco-Paulo, A, Gübitz, GM. 2001. Indigo degradation with purified laccases from Trametes hirsuta and Sclerotium rolfsii. Journal of Biotechnology; 89: 131139. 